\title{
A Content Analysis of Teen-Favored Celebrities' Posts on Social Networking Sites: Implications for Teen Fame-Valuation
}

\author{
Keren Eyal ${ }^{1}$, Tali Te'eni-Harari ${ }^{2}, \&$ Keshet Katz ${ }^{3}$ \\ ${ }^{1}$ Sammy Ofer School of Communications, Interdisciplinary Center (IDC) Herzliya, Herzliya, Israel \\ 2 Business School, Peres Academic Center, Rehovot, Israel \\ ${ }^{3}$ StoreNext Research and Strategy, Petah Tikva, Israel
}

\begin{abstract}
The aspiration of young people for fame - a wide public recognition - has risen in recent years. This fame-valuation is a concern for scholars, educators, and parents as it has been linked with teen self-focused aspirations, narcissism, and materialism. This rise in the value of fame has been linked to two trends: teens' increased attraction to celebrities and their use of social networking sites (SNSS). SNSs have changed the landscape of celebrity media presence compared to traditional media and enable a shift in balance between a professional and personal focus in the celebrity's brand image. Such a balance might have implications for the relationships audiences form with celebrities and, by extension, for adolescent fame-valuation. The current study examines the SNS (Facebook and Instagram) posts of teen-favored celebrities in order to map the characteristics of the messages to which adolescents are heavily exposed, that might reinforce their fascination with fame. The study is based on a content analysis of 1,075 posts by 24 teen-favored local and foreign celebrities in Israel. The study finds that celebrities' SNS posts lack depth in personal self-disclosure and are rather strongly focused on their professional lives - job-related activities, achievements, and self-promotion. Though SNSs present limited gatekeeping restrictions, celebrities choose to present a controlled image of themselves that is unprovocative, as evident in their promoted values, exhibited lifestyle, and physical representation.
\end{abstract}

Keywords: Celebrities; social networking sites; adolescents; parasocial relationships; fame-valuation

\section{Introduction}

Recent years have seen a surge in teen aspiration for fame. It seems that "being famous" or even just being associated with a famous person, has become a teen fixation, some even say obsession (Uhls \& Greenfield, 2012). In a survey of 9 to 15 years olds, $33 \%$ indicated that being famous is either somewhat important, important, or very important (Jayson, 2013). Fame-valuation is a concern for scholars, educators, and parents as it has been linked with such characteristics as teen self-focused aspirations, narcissism - an "inflated sense of self-worth" (Greenwood, 2013, p. 224) - and materialism (e.g., Fu et al., 2015; Uhls et al., 2014).

The high value placed on fame among young people has been suggested to be linked to the increased value placed on being famous in tween television shows over the last half century (Uhls \& Greenfield, 2011). The increased appreciation of fame has also been suggested to be linked to two trends: teens' increased attraction to celebrities and their use of social media and social networking sites (SNSs). Celebrities are famous people who use their mediated image to practice stardom (Marwick \& boyd, 2011a); celebrities possess a "range of socially desirable personal attributes and skills which lead to the widespread recognition and creation of popular and influential individuals" (Moraes et al., 2019, p. 5). Celebrities embody and represent issues of fame and increasingly serve as role models for adolescents (Uhls \& 
Greenfield, 2012). Social networking sites provide adolescents a new sense of intimacy and interaction with these role models as they "friend" and follow favorite celebrities online, creating parasocial relationships (PSRs) - one-sided friendships with them (Greenwood, 2013). The exposure to celebrities' praised talent and desired lifestyle via SNSs may heighten celebrity and fame adoration even further for young audiences (Soukup, 2006).

The current study employs a content analysis methodology to characterize the SNS self-constructed presence of teenfavored celebrities in order to understand the messages to which adolescents are exposed in these profiles and which could be potentially linked with fame valuation. By mapping the characteristics of SNS messages to which adolescents are heavily exposed, light could be shed on what might draw young people to follow these celebrities and, ultimately, reinforce their obsession with fame.

\section{Adolescents' Attraction to Celebrities}

The main developmental task facing adolescents is developing a clear sense of personal identity, understanding who they are, their core values, and their commitment to self-defined beliefs (Erikson, 1968). To do so, adolescents must engage in self-reflection as well as in surveillance of their environment and self-comparison with others who surround them. Both real-life figures as well as mediated personae serve as sources for social comparison, providing information, mentoring, and role modeling for anything from physical appearance to social interactions (e.g., Gleason et al., 2017; Te'eni-Harari \& Eyal, 2015). Especially for young people, cues often associated with celebrities, such as popularity and attractiveness, are important markers of prestige, which may lead to a preference to rely on these individuals as role models (Jiménez \& Mesoudi, 2019). Thus, developmentally, celebrity adoration is an important marker of the adolescent stage (Maltby et al., 2003).

Since the early days of mass media, celebrity attraction relied on press coverage of celebrities, filtered through traditional gatekeepers as journalists and the paparazzi. Such traditional media coverage tended to focus on the professional activities of the celebrities to which gatekeepers had access. Alongside the professional, traditional media also made attempts to uncover the person behind the famous persona by revealing private issues about the celebrity (Holmes, 2005; Van den Bulck et al., 2017). Traditional paparazzi photos focused on intimate and private events in the celebrities' lives. More recently, photographs, which have become the mainstream of news about celebs especially online, focus more on the everyday activities of famous people (Mortensen \& Jeslev, 2014). As part of the quest to present celebrities as ordinary people, such photography has thus been increasingly characterized by an anti-aesthetic, almost amateur, quality (McNamara, 2011).

Social networking sites, which have become increasingly popular in recent years, have changed the landscape of celebrity media presence since the early days described above. SNSs allow celebrities more control over their desired brand and personal image, self-constructed without the intervention of traditional media gatekeepers (Thomas, 2014). In the hands of the celebrities themselves (or their social media managers who work on their behalf), SNSs now also potentially allow for an even more personal glimpse into the celebrities' lives. As will be detailed, as a result, SNSs may change the nature of adolescents' relationships with celebrities relative to traditional media.

\section{Social Networking Sites and Their Link to Adolescents' Celebrity Attraction}

Celebrity presence on SNSs is especially important for adolescents as teens have in recent years shown the greatest increase in use of social media on a regular basis (Common Sense Media, 2015; Dror \& Gershon, 2012). Three-quarters of Israeli teens - the country in which the current study was conducted - use social media on a daily basis and are the most heavily engaged age group across all its digital activities (Dror \& Gershon, 2012). Through its constant mobile availability and interpersonal affordances (e.g., staying in touch with geographically distant friends and acquaintances, Dror \& Gershon, 2012; Wiederhold, 2012), social networking sites likely satisfy multiple developmental needs for adolescents. SNSs enable teens to engage in identity exploration through their self-presentation (e.g., constructing "stories," uploading pictures, Mascheroni et al., 2015; Spies Shapiro \& Margolin, 2014; Siibak, 2009; Tzavela \& Mavromati, 2013). Celebrity interest is a strong motivator for social media use especially among teens and young adults (Greenwood, 2013; Wiederhold, 2012). And, indeed, many teens have been quick to "friend" celebrities on SNSs and have made these personae some of the most highly followed figures on SNSs (boyd, 2007; Madden et al., 2013).

Social networking sites offer a new playing field for celebrities. First, the nature of the celebrities themselves has changed, with a shift toward more celebrities that are not associated with a particular profession, such as singers and actors (e.g., 
Kim Kardashian) and micro-celebrities such as YouTubers (Kurtin et al., 2018). Second, SNSs allow for a more interactive and intimate connection between celebrities and audiences as the celebrities themselves can now post personal information, also about their intimate lives (Bond, 2016; Marshall, 2014). In this, SNSs enable changing the traditional balance between professional and personal focus on the celebrity in the media. By emphasizing the personal aspects of their own lives, celebrities can attract audiences and maintain more powerful parasocial relationships with them, which are essential for their self-branding and self-promotion (Chen, 2016; Geurin-Eagleman \& Burch, 2016; Stever \& Lawson, 2013).

\section{Parasocial Relationships With Celebrities, SNSS, and Adolescent Fame-Valuation}

Parasocial relationships with mediated figures are one-sided friendships that audience members form with personae to whom they are exposed through the media (Horton \& Wohl, 1956). Similar to real-life relationships, PSRs are based on enhanced trust in, familiarity with, and attraction to the mediated persona (Fehr, 1996; Rubin \& McHugh, 1987; Tian \& Hoffner, 2010). PSRs with mediated personae are maintained by audience members by making investments in the relationships, devoting time and effort to in them, and through their feelings of commitment to the relationship (Eyal \& Dailey, 2012). Exposure to celebrity posts on SNSs has been found to be linked to perceptions of trust and loyalty to the celebrity - two important factors for brand impression - through the mediation of online parasocial interactions (withinexposure experiences of friendships, Dibble et al., 2016), which may build up to enduring PSRs (Ledbetter \& Redd, 2016; see also Labrecque, 2014; Phua et al., 2017).

Based on knowledge about PSRs from traditional media, Marwick and boyd (2011a) suggested that celebrities should use their SNS profiles to create a sense of intimacy with their followers. In parallel to traditional media in which mediated personalities "break the $4^{\text {th }}$ wall," that is, speak directly to the audience (Auter, 1992), celebrities are expected to take advantage of the natural direct address of the audience afforded by SNSs to appear open and responsive to their audience (Labrecque, 2014). This can be done by providing personal information to decrease uncertainty, using common affiliative language, and interacting with other celebrities on the SNS. Another suggestion that is commonly raised for celebrities to maintain a PSR with audiences is to create an emotional connection with followers and, for this purpose, to communicate honesty, and, importantly - authenticity (Lunardo et al., 2015). Authenticity can include two dimensions: perceived similarity to the audience member and perceived realism (Click et al., 2013; Tsay-Vogel \& Schwartz, 2014). As such, it is important that celebrities appear enthusiastic, reachable, receptive, and responsive; that they reveal and share personal anecdotes (Duboff, 2016; Lunardo et al., 2015), especially information that appears genuine (Kowalcyzk \& Pounders, 2016). Celebrities' self-disclosure should be both broad (that is, cover many topics, both personal and professional) and deep (not superficial but rather intimate; Kim \& Song, 2016). The invitation to peek into the personal lives of the celebrity is especially appealing to young audiences - as evident in the higher rates of "likes" to posts from non-professional settings than professional ones - as it is only enabled through SNSs and much less on more traditional media platforms (Tukachinsky et al., 2019).

On the part of the audience, PSRs are important as they relate to people's self-perceptions, vulnerability to mediated persuasion effects, and even political decisions (Gabriel et al., 2018; Moyer-Gusé, 2008). Especially for adolescents, parasocial relationships with celebrities are common and important as they gratify their developmental need for attachment, provide a feeling of similarity to others, and offer opportunities for them to learn about themselves and their relationships, and are associated with their emerging attitudes and perceptions about real-world issues (Aubrey et al., 2014; Behm-Morawitz et al., 2019; Bond, 2016; Click et al., 2013; Giles \& Maltby, 2004).

PSRs which may be enhanced through SNS exposure to and following of celebrity profiles have the potential to positively associate with adolescent fame-valuation. Research has shown that exposure to celebrities through SNSs is associated with increased parasocial interactions and relationships. This is probably due to celebrity self-disclosure and also because of the robust presentation of an alluring life-style and prestige which equates fame with success and is widely appealing to youth (Chung \& Cho, 2017; Kim \& Song, 2016; Rui \& Stefanone, 2016). PSR, in turn, as an indicator of involvement with the celebrities, has been shown to link with interests in certain aspects of fame, such as the widespread visibility fame involves (Greenwood et al., 2018). Greenwood et al. (2018) write that "feeling connected to a famous person may provide vicarious feelings of worth or value for someone who seeks the spotlight themselves" (p. 241) and, in this, perhaps PSRs with celebrities perpetuate fame-valuation among adolescents. Thus, it is important to understand the extent to which celebrity self-constructed SNS presence highlights personal versus professional information. 


\section{Research Questions}

Despite the seemingly unequivocal expert recommendation to focus their SNS profiles on their personal lives, the decision of celebrities (and their social media management team) with regard to the balance between presenting personal versus professional information is challenging. On the one hand, SNSs enable the self-impression management of celebrities, their own construction, free from traditional gatekeepers, of their brand image through careful staging to support their self-promotion goals (Cohen \& Tyler, 2016; Hull \& Lewis, 2014; Marshall, 2010). On the other hand, SNSs require much self-censorship on the part of celebrities who cannot risk over-exposure, or having audiences exposed uncontrollably to sensitive or controversial topics and opinions (Marwick \& boyd, 2011b).

In light of this challenge and the extensive amount of time and interest of adolescents in celebrities and their lives, the current study seeks to examine the characteristics of celebrity posts in their profiles on leading SNSs. Specifically, the study seeks to identify whether and how celebrities utilize the affordances of SNSs to attempt to enhance the young audience's parasocial ties with them, which may then be linked with increased teen fame-valuation. Based on knowledge regarding parasocial relationships, the study places an emphasis on both the breadth and depth of personal selfdisclosure in celebrity posts as well as on their promotion of a physically attractive and appealing celebrity life-style that is likely to appeal to youth's fame aspirations. To do so the study examines the entire post, including the text and visuals included within it, which have become central components even in news reports, especially of celebrities (Smith et al., 2009).

The breadth of topics addressed in SNSs by the celebrity - that is, how many and how different topics and issues are covered - is important as this has been linked with greater interpersonal attraction toward the profile owner, which is mediated by an increased sense of attributional confidence, especially in the early stages of relational development (Baruh \& Cemalcilar, 2018). The depth of self-disclosure - the sharing of personal experiences, feelings, and opinions on celebrity SNS profiles is also critical as studies find that greater exposure to content on SNSs is linked with a stronger sense of intimacy and stronger feelings toward the profile owner (Chia \& Poo, 2009). Despite the attempts of traditional and online media to uncover the person behind the famous persona (Holmes, 2005; Van den Bulck et al., 2017), the breadth and depth of disclosure on personal profiles on SNSs sheds light into how the celebrities themselves manage their public-private selves (Marshall, 2010). As more - and deeper - personal information about themselves is available to the celebrities themselves (As compared to other media sources), it is interesting to examine the professional-personal balance of information that they choose to present about themselves in their SNS posts. Thus, the study asks:

RQ1: What is (a) the breadth of issues and (b) the depth and extent of personal and emotional self-disclosure in celebrities' SNS posts?

Beyond the topics and issues addressed in celebrity SNS posts, it is important to consider the external appearance and lifestyle that the celebrities choose to exhibit in their posts as these too, as indicated in the review above, may be related to PSR establishment and maintenance as well as to fame-valuation. Here, too, a continuum of personal to professional representation is possible. Visuals of celebrities are important as they create a sense of immediacy, a feeling of being close to the celebrities, capturing a moment, and inviting gossip and follow-up communication (Mortensen \& Jeslev, 2014). Visuals are also important as they most clearly present the physical appearance of the celebrity, which can contribute to interpersonal attraction. In recent years, celebrity photography has been on the rise with much demand especially for intimate and revealing shots (McNamara, 2011). It is interesting to examine how the celebrities themselves (or through their social media management team) choose to physically represent themselves in their SNS profiles. For example, to what extent do celebrities choose to post photos of themselves that are professional versus amateur, to what extent do they reveal personal aspects of themselves in these photos (such as their more private body parts of personal household), etc.

A unique celebrity-related aspect of appearances is the display of a "celebrity lifestyle" - the celebrity's engagement in celebrity-oriented events and parties, interacting with other celebrities, engagement with alcohol, cigarettes, physical activity, and sexual activity, and promoting a sense of materialism by focusing on clothes, shopping, and products (e.g., Lewallen et al., 2016; Marwick \& boyd, 2011a). A celebrity lifestyle - which is often communicated through visual means - likely marks an ideal for which to aspire, on the one hand, yet on the other, communicates a sense that it is attainable and ordinary and makes it easier for fans to imagine being close friends with the celebrity. Thus, the study asks: 
RQ2: What is the nature of (a) celebrities' self-physical representation and (b) celebrities' reflection of a celebrity lifestyle in their SNS posts?

\section{Method}

\section{Sample}

The content analysis sample consisted of the last 25 posts (as of July 27, 2017) on each of the SNS Instagram and Facebook (when available) for each of 24 celebrities identified as favorites among Israeli teens. These SNSs were chosen as they involve the greatest participation of Israeli adolescents, (75\% of Israeli teens are active on Facebook and $61 \%$ of Israeli teens are active on Instagram) second and third only to Whatsapp, which is less focused on celebrities (Israel National Council for the Child, 2017). The 24 celebrities were chosen in three categories representing the top favorite media-based famous influencers among Israeli teens: the top eight favorite Israeli female celebrities, the top eight favorite Israeli male celebrities, and the top eight favorite international celebrities (males and females combined). Favorite celebrities were selected if they met at least two of the following criteria, focused on Israeli entertainment and teen media outlets: (a) Final contestant or winner of the 2015 Teen Choice Awards of the Israeli teen magazine Rosh Echad, (b) Appearance on a June 2015-June 2016 cover of the teen magazine Rosh Echad, (c) Final contestant or winner of the 2015 Children's Choice Awards of the Israeli Children's Television Channel, (d) Appearance on a June 2015-June 2016 cover of the Israeli entertainment magazine Pnai Plus, (d) Ranked on the 2015 "The Beautiful and Right List" of the Israeli entertainment magazine Pnai Plus, and (e) Appearance on a June 2015-June 2016 cover of the Israeli teen magazine Ma'ariv La-Noar. Only formal SNS profiles operated by the celebrities or their social management team (that is, not fan pages) were included in the sample and only personal SNS profiles were chosen (that is, profiles of duos or bands were not included). Seven celebrities had an active profile on only one of the SNSs (Instagram or Facebook), thus resulting in a sample of 1,075 posts.

\section{Coding and Inter-Coder Reliability}

Table 1. Variables Coded Across Different Units of Analysis to Answer the Research Questions.

\begin{tabular}{|c|c|c|c|c|c|}
\hline Research Question & Unit of Analysis & & & & \\
\hline & $N=1,075$ & $N=1,075$ & $N=1,055$ & $N=786$ & $N=1,074$ \\
\hline \multirow{2}{*}{$\begin{array}{l}\text { RQ1a - } \\
\text { Topics/issues } \\
\text { addressed }\end{array}$} & Subject (.94) & & & & Topic (.95) \\
\hline & $\begin{array}{l}\text { Appeal to teenagers } \\
(.90)\end{array}$ & & & & Values (.93) \\
\hline $\begin{array}{l}\text { RQ1b - } \\
\text { Celebrities' } \\
\text { personal and } \\
\text { emotional self- } \\
\text { disclosure }\end{array}$ & & $\begin{array}{l}\text { Personal self- } \\
\text { disclosure (.92) }\end{array}$ & & & \\
\hline \multirow{3}{*}{$\begin{array}{l}\text { RQ2a - } \\
\text { Celebrities' } \\
\text { physical } \\
\text { representation }\end{array}$} & & & Professionalism (.81) & Presence (.97) & \\
\hline & & & & Grooming (.80) & \\
\hline & & & & Physical attractiveness (.79) & \\
\hline \multirow{2}{*}{$\begin{array}{l}\text { RQ2b - } \\
\text { Celebrity life-style } \\
\text { as reflected in the } \\
\text { post }\end{array}$} & & Celebrity life-style (.96) & Alcohol (.99) & Sexuality (.98) & \\
\hline & & & Cigarettes (1.00) & Physical activity (.97) & \\
\hline
\end{tabular}

Note. Scott's Pi inter-coder reliability score in parentheses next to each variable.

Eight undergraduate students served as coders for this study. They underwent extensive training over several weeks with posts not included in the sample. Then, the sample was coded throughout several weeks. Each post in the sample was 
coded by one coder. Throughout the coding period, the evaluation of inter-coder reliability was done regularly, using 43 posts coded by all coders (one post from each SNS for each celebrity, randomly selected from the final sample). Coders' decisions were compared using the Scott's pi formula, as in past large-scale studies (Potter \& LevineDonnerstein, 1999). Each variable's final reliability was calculated by averaging the scores for all reliability tests. The reliability score for each variable appears in Table 1.

\section{Coding Scheme}

\section{Units of Analysis}

The central unit of analysis in this study was the post. A second unit of analysis was the celebrity him- or herself in the post. In addition, within each post, any visual (i.e., picture or video) was coded as another unit of analysis. Within each visual, the celebrity him- or herself served as a fourth unit of analysis. A fifth unit of analysis was the text of the post.

To answer each of the research questions, variables were coded across different units of analysis.

Table 1 summarizes all coded variables within each unit of analysis as used to address each of the research questions in the study. Table 2 provides information about all coded levels within each variable. The coding scheme was developed explicitly for the current study and, when possible, codes were based on previous research reported in the literature, as indicated below.

Table 2. Summary of Results RQ1a - Topics/Issues Addressed in the Post ( $n, \%)$.

\begin{tabular}{l} 
The Post \\
$N=1,075$ \\
$N=1,074 \quad$ Text \\
\hline
\end{tabular}

- $\quad$ Professional life $(645,60.00 \%)$

- $\quad$ Self-promotion $(422,39.26 \%)$

- $\quad$ Personal life $(256,23.81 \%)$

- $\quad$ Promotion of goods $(99,9.21 \%)$

- $\quad$ Political/social causes (37, 3.44\%)

- $\quad$ Nostalgic $(13,1.21 \%)$

- Other $(25,2.33 \%)$

Appeal to teenagers:

- $\quad$ No $(865,80.47 \%)$

- $\quad$ Yes $(210,19.53 \%)$
- $\quad$ Celebrity adoration (460, 42.83\%)

- $\quad$ Talent $(363,33.80 \%)$

- $\quad$ Partying $(111,10.34 \%)$

- Mentions of the celebrity in the media $(86,8.00 \%)$

- $\quad$ Celebrity life-style (84, 7.82\%)

- Clothing/fashion/accessories $(75,6.98 \%)$

- Politics/social causes (48, 4.47\%)

- $\quad$ Physical appearance $(41,3.82 \%)$

- $\quad$ Food (36, 3.35\%)

- $\quad$ Physical activity $(19,1.77 \%)$

- Health $(12,1.12 \%)$

- $\quad$ Alcohol $(6,0.56 \%)$

- $\quad$ Body shape $(2,0.19 \%)$

- Sexuality/cigarettes (1, 0.09\%, each)

- Diet/weight/ the thin ideal (0,0.00\%, each)

- $\quad$ Other $(225,20.95 \%)$

Values:

- $\quad$ Equality/liberalism $(465,43.20 \%)$

- Community $(344,32.03 \%)$

- Women's empowerment (119, 11.08\%)

- $\quad$ The thin ideal $(105,9.78 \%)$

- $\quad$ Enjoying life $(93,8.66 \%)$

- $\quad$ Familialism \& Self-esteem (30, 2.79\%, each)

- Celebrity/adoration (20, $1.86 \%)$

- Health $(14,1.30 \%)$

- $\quad$ Friendship $(13,1.21 \%)$

- Materialism $(12,1.12 \%)$

- $\quad$ Aesthetics (1, 0.09\%)

- Other $(49,4.56 \%)$ 


\section{The Post Unit}

The post's subject was identified as one or more of the following topics: the celebrity's personal life, professional life, political/social causes, promotion of goods, self-promotion (e.g., advertising an upcoming appearance or concert), nostalgic (e.g., childhood pictures), or other. This list was composed based on a cursory review of different celebrities' (not necessarily related to the current sample) SNS profiles as well as previous research which has indicated what topics addressed in SNS profiles might be important for audiences' relationships with celebrities (e.g., celebrities' societal engagements, Panis \& Van den Bulck, 2014) to determine possible categories. Appeal to teenagers - the direct reference in content to adolescents using relevant terminology, photos of teenagers, references to events or activities for youth was coded in each post.

\section{The Celebrity Unit}

Personality characteristics of the celebrity were coded so that any personal quality that was prominent in the post was indicated, including being compassionate, friendly, family-orientated, romantic, humorous, intelligent, self-confident, talented, professional (possessing high work ethic), and other. The extent of personal self-disclosure of the celebrity was coded to identify the openness of the celebrity in the post, the depth of revelation of intimate aspects of the celebrity's life, the sense of authenticity and transparency communicated by the post. Characteristics of self-disclosure were chosen based on past research (e.g., Baruh \& Cemalcilar, 2018; Kim \& Song, 16). This was coded using three levels: no selfdisclosure at all, some self-disclosure, and a high degree of self-disclosure. The extent to which the post reflects a celebrity life-style (that is, outside of the professional work of the celebrity, the extent to which the celebrity attends special celebrity events, participates in product/brand launches, receives gifts intended for celebrities, or hangs out with other celebrities to which the general public does not have access) was drawn from Lewallen et al. (2016) and was coded in four levels: no signs of a celebrity life-style, some signs of a celebrity life-style, a celebrity life-style is the most central topic of the post, or undetermined.

\section{The Visual (Pic/Video) Unit}

Unitizing agreement - the identification of the presence of a visual in the post - was high as was the agreement of whether the visual was a picture or video. The location or background of the visual was coded as either indoors (but not in the bedroom or bathroom), in the bedroom, in the bathroom, a professional setting (e.g., a studio), outdoors (e.g., restaurant, beach), or undetermined. The extent of visual professionalism - that is, whether the visual was taken by a professional photographer in a professional setting - was coded as either professional with formal credit, amateur, or undetermined. The presence of alcohol or cigarettes - coded as mentioned or depicted or as not present.

\section{The Celebrity in the Visual Unit}

The presence of the celebrity in the visual was coded. The body presentation of the celebrity in the visual was coded as not shown at all, head only, lower half body, upper half body, or entire body. Clothing of the celebrity, when appearing in the visual, was coded as elegant, sportive, beach wear, home style (e.g., pajama), casual look, or undetermined. Body exposure - the extent to which the celebrity's clothing reveals skin - was coded as no exposure at all (e.g., a long coat), appropriate exposure for the clothing (e.g., arms exposed when wearing a short-sleeved shirt), beach wear, underwear/bra, high exposure for the clothing item (e.g., a high-slit skirt, a sleeve that slips off the shoulder), implicit nudity (e.g., hiding behind a large towel that implied nudity underneath), full nudity, or undetermined. Grooming was determined by the extent to which the celebrity in the visual seems to have devoted effort to styling, including hair and clothing choices, facial treatment, make-up, etc. The categories included: Not groomed at all, slightly groomed, highly groomed, or undetermined. The celebrity's physical attractiveness was determined, similar to previous content analyses (Eyal \& Finnerty, 2009), by the overall appearance as composed by the celebrity's appealing body shape, symmetrical facial features, well groomed hair, clean skin appearance, etc. and was coded as very unattractive, attractive, very attractive, or undetermined. Physical activity as engaged in by the celebrity in the visual was coded as explicitly shown (e.g., the celebrity is shown jogging), implicitly shown (e.g., the celebrity is shown sweating and drinking from a sports water bottle), or not at all. Sexuality in the visual was coded, based on definitions of previous studies (Eyal et al., 2007), as any presence or hint of a sexual activity or relationship in the visual, including physical contact that implies intimacy. The categories were: no sex at all in the visual, the celebrity is involved in implicit sexuality, or the celebrity is involved in explicit sexuality. 


\section{Text Unit}

The topic of the post's text was coded as any of the following (more than one could be coded to the extent that they were mentioned in the text): body shape, diet/weight, physical appearance, the thin ideal, health (unrelated to weight or body shape), clothing/fashion/accessories, physical activity, sexuality, cigarettes, alcohol, food, partying, celebrity adoration, celebrity life-style, mentions of the celebrity in the media, the celebrity's talent, political/social cause, and other. The values promoted in the text were identified as any of the following (more than one could be coded per post): women's empowerment, equality/liberalism, community, friendship, health, self-esteem, the thin ideal, materialism, familialism, aesthetics, enjoying life, celebrity/adoration, and other. Values were selected and adapted based on previous research about values, in general, and about values associated with celebrities in the media, specifically (e.g., Gorin \& Dubied, 2011; Saleem et al., 2015). The tone of the text - or to what extent the content is treated with seriousness and gravely - was coded as very serious, combining seriousness with humor, or very humorous.

\section{Results}

The 24 favorite celebrities included 11 actors (45.83\%), 6 singers (25.00\%), 6 actors/singers (25.00\%), and 1 fashion blogger (4.17\%). They included 11 men (45.83\%) and 13 women (54.17\%), 16 Israelis (66.67\%) and 8 non-Israeli celebrities (33.33\%), with an age range of $15-40$ years $(M=24.75, S D=4.71)$. On average, the 1,075 posts included in the sample received 151,082.18 "likes" per post (range: $0-6,100,000, S D=475,618.68$, median $=6645.00$, mode $=1,100,000$ ) and $3,571.28$ comments (range: $0-518,436, S D=22,963.10$, median $=135.00$, mode $=00.00$ ). Most posts included a visual (either a picture of video, $N=1,016,94.51 \%)$ and except for one post, all posts included texts $(N=1,074,99.91 \%)$.

\section{The Breadth and Depth of Topics Addressed in Posts and the Extent of Self-Disclosure They Involve}

To address RQ1a (see Table 2 for a summary of the findings), the subjects addressed in posts were examined both overall in the posts and in the texts of the posts. The most common subject addressed in the posts (more than one topic could be identified in each post) was the celebrities' professional lives, including pictures from television series sets, reflection on a recent performance, etc. For example, Israeli make-up and lifestyle blogger Ashley Waxman Bakshi's Facebook post from March 16 shared a post from another personal care blog that praised Bakshi's professional success; The shared post praised Bakshi's "history making" international collaboration in creating her own lipstick along with her skills and the fact that "she breathes make-up." The second most common topic in celebrity posts was self-promotion, including information about upcoming concerts or appearances by the celebrity. For example, actress Eliana Tidhar's Instagram post promoted the upcoming final season of her television series Galis by posting a poster of the show including the words "Tomorrow!!!" and "Starting! 14:25;" she wrote: "Hard to believe, but tomorrow begins the final season." Following these, the most common topic in posts was the celebrities' personal lives, including posts about their family, non-work related friends, or home. These topics were followed by posts that promoted goods not directly associated with the celebrity him- or herself, posts about political or social events or causes (e.g., donations, events to which the celebrity enlisted, etc.), only a handful of nostalgic posts. An example of a political-oriented post is Demi Lovato's Facebook post from July 21 in which she is seen wearing a tee shirt supportive of Hillary Clinton's campaign. Only a minority of posts about a fifth of them - included a direct appeal to teen audiences. An example of a post that appealed to a teen audience is Tom Baum's (an Israeli actor) Facebook post from March 20 in which he is pictured with one of his co-stars - who is also a teen-favored celebrity - from the Israeli teen television show Galis and the simple text hints that they are now filming the show.

When analyzing the texts in celebrity posts in this sample (more than one topic could be identified), it was found that the most common topics were adoration of the celebrity and the celebrity's talent. By a far distance, topics covered included parties or celebrations in which the celebrities took part, mentions of the celebrities in the media, celebrity lifestyle, and clothing/fashion/accessories. Less than $5 \%$ of posts' texts addressed politics/social causes, physical appearance, food, physical activity, alcohol, body shape, health, and sexuality/cigarettes. The values promoted in the posts' texts included, in descending order (more than one value could be promoted in the text) equality/liberalism and community. These were followed by a large distance by the values of women's empowerment, the thin ideal, and enjoying life. Only less than $3 \%$ each included the values of famililism, self-esteem, celebrity adoration, health, friendship, and materialism. Only one posts' text promoted aesthetics.

To address RQ1b (see Table 3 for a summary of the findings), the study examined the depth of personal revelations in which celebrities engage in their posts and the extent to which they expose personal aspects of their lives and inner 
selves. Overall, the large majority of posts did not involve any self-disclosure, they only provided information or superficial expressions of emotion rather than offering personally intimate information about the celebrity to which the audience is not generally privy or reflecting deep emotional exposure. Only slightly more than $10 \%$ of the posts included some self-disclosure and only 4 posts included a high degree of self-disclosure. An example of a post with extensive self-disclosure is Israeli actor Daniel Moreshet's Facebook post in which he publicized a letter written to him by his mother at the finale of his television series, Galis. In this letter, his mother returns back to her son's early days as an actor, describing the teen fan reaction and loss of privacy and how her son's life has changed with this publicity over the years. She writes of her love and pride of him as she writes of his personality and reaction to this change in his life over the years. Relatedly, the large majority of texts in posts were very serious in tone, slightly more than $10 \%$ combined a serious and humorous tone, and only a small minority of the texts were very humorous in tone.

Table 3. Summary of Results RQ1b-Celebrities' Personal and Emotional Self-Disclosure in the Post (n, \%).

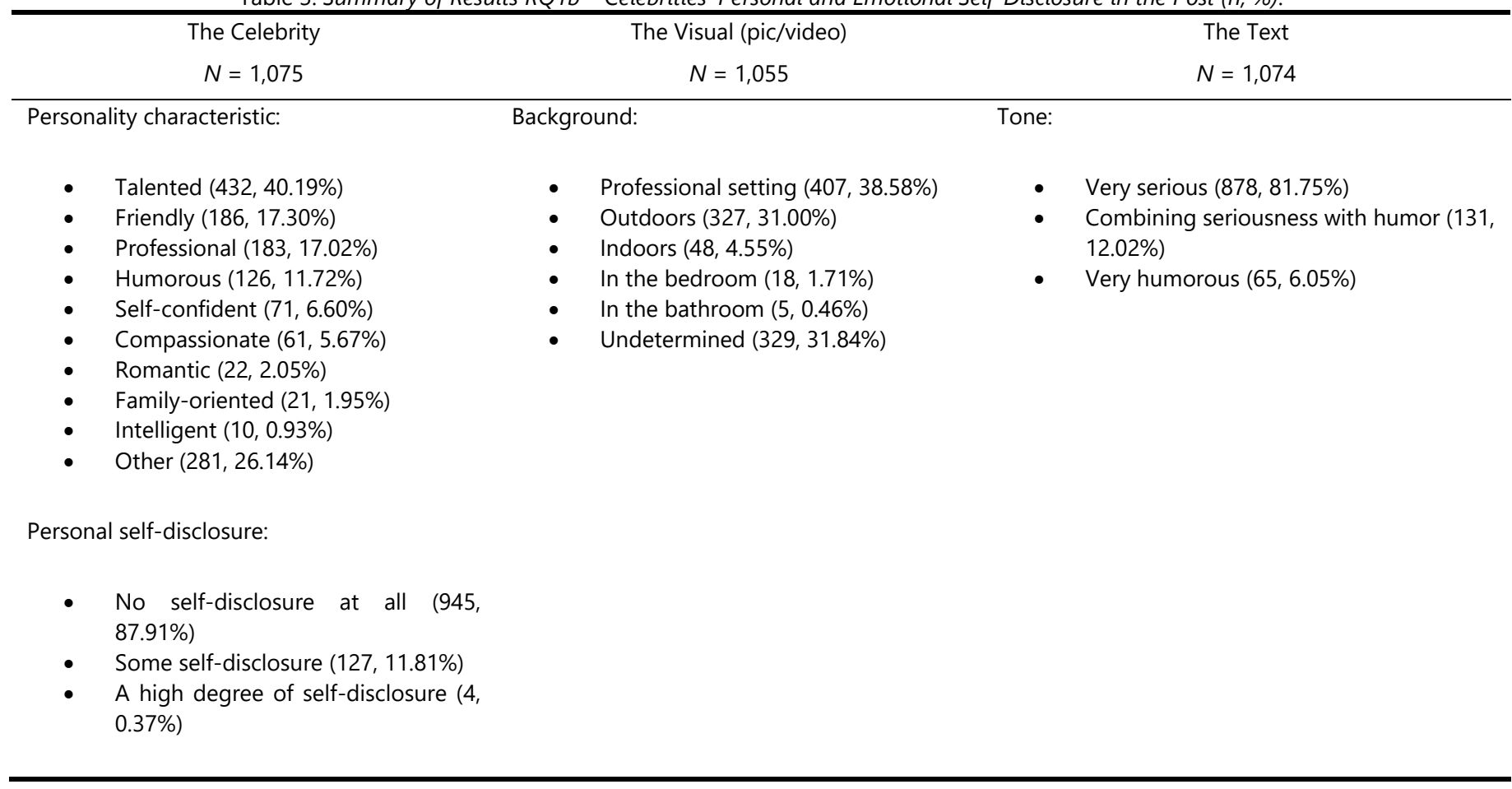

The posts were examined also to determine which personality characteristics of the celebrities were evident from the posts (visuals and texts considered). The most prevalent personal characteristic of the celebrity, appearing in $40 \%$ of the posts, was their talent. For example, Noa Kirel is an Israeli teen singer whose Facebook post reposted with gratitude an announcement by a popular radio station that her song has made their playlist; in this announcement, the station introduced Noa as "one of the greatest promises in Israeli pop, with a record of an Internet phenomenon, [and] a production that sounds as though it's from abroad," clearly praising her talent. This was followed by a large distance (appearing in only less than a fifth of all posts) by friendliness, professionalism, and sense of humor. Personal characteristics that resonated in less than $10 \%$ of posts included self-confidence, compassion, romanticism, familyorientation, and intelligence.

As another indicator of self-disclosure and consistent with the focus on the celebrity's professional life, the most common background of the visuals in posts (more than one location could be identified in each visual) was a professional setting such as a studio followed by outdoors. By a much greater distance (in less than $5 \%$ of the visuals each), visuals in posts were set indoors, such as a home, bedroom, or bathroom.

\section{The Physical Representation and Exhibition of a Celebrity Life-Style in Posts}

In answering RQ2a (see Table 4 for a summary of the findings), the celebrities appeared in 786 of the posts' visuals ( $74.50 \%$ of the 1,055 posts with a visual). More than half of these visuals featured the celebrity's upper half body. This was followed by the celebrity's entire body in about a third of photos. Less than $10 \%$ of photos exposed only the head and only a handful revealed the lower half body of the celebrity. In terms of clothing, casual clothing was most common, 
in nearly half the photos. This was followed by elegant clothes in about a quarter of the photos. Much less frequent were the celebrities shows in beach wears, sportive clothes, and pajama or home-wear. The celebrities mostly exposed their bodies in an appropriate manner for their clothing, in more than half of the photos. There was no body exposure at all in a fifth of photos. In less than $10 \%$ of visuals did the celebrities reveal more skin than necessary for their clothing and they were extremely rarely shown partially or fully naked. For example, Demi Lovato shared an Instagram photo in which she is seen lying with her half-body partially naked on a bed with the text "Scared of what I might say Cause I'm at the edge."

Table 4. Summary of Results RQ2a - Celebrities' Physical Representation in the Post (n, \%).

$N=1,055$

$N=786$

Professionalism:

- Professional with credit $(404,38.29 \%)$

- $\quad$ Amateur $(283,26.82 \%)$

- Undetermined $(368,34.88 \%)$
Body representation:

- $\quad$ Not shown at all $(269,25.50 \%)$

- Upper half body $(447,56.87 \%)$

- $\quad$ Entire body $(259,32.95 \%)$

- $\quad$ Head only $(70,8.91 \%)$

- $\quad$ Lower half body $(6,0.76 \%)$

Clothing:

- $\quad$ Casual look $(377,47.96 \%)$

- $\quad$ Elegant $(207,26.34 \%)$

- $\quad$ Beach wear $(41,5.22 \%)$

- $\quad$ Sportive $(29,3.69 \%)$

- Home style (e.g., pajama) $(10,1.27 \%)$

- $\quad$ Undetermined $(122,15.52 \%)$

Body exposure:

- Appropriate exposure for the clothing $(465,59.16 \%)$

- $\quad$ No exposure at all $(161,20.48 \%)$

- High exposure for the clothing item $(65,8.27 \%)$

- $\quad$ Beach wear $(31,3.94 \%)$

- Implicit nudity $(5,0.64 \%)$

- $\quad$ Full nudity $(3,0.38 \%)$

- Underwear/bra $(1,0.13 \%)$

- Undetermined $(51,6.49 \%)$

Grooming:

- $\quad$ Highly groomed $(355,45.17 \%)$

- $\quad$ Slightly groomed $(332,42.24 \%)$

- $\quad$ Not groomed at all $(20,2.54 \%)$

- Undetermined $(79,10.05 \%)$

Physical attractiveness:

- $\quad$ Attractive $(390,49.62 \%)$

- $\quad$ Very attractive $(321,40.84 \%)$

- Very unattractive $(11,1.40 \%)$

- Undetermined $(64,8.14 \%)$

Of the visuals in which celebrities appeared, the celebrities were nearly equally highly groomed and slightly groomed. Only very rarely were they not groomed at all. The celebrities were considered as attractive in nearly half the photos and very attractive in an additional two-fifths of the photos. Only in 11 visuals were the celebrities very unattractive, such as Tuval Shafir's Instagram post in which he expresses excitement toward rapper Pharrell Williams' upcoming performance in Israel and includes a photo in which he digitally manipulated his face in humor to appear uneven, unsymmetrical, with crooked and fat features with a pink sweatband on his forehead; this is a clear exception to Shafir's usually thin and 
attractive, baby-face look. The professionalism of the visuals was nearly equally divided between professional with credit, amateur, and undetermined.

In addressing RQ2b (see Table 5 for a summary of the findings), the study examined the extent to which specific behaviors associated with one's life are reflected in the posts and shed light on the celebrity's life-style and pastime activities. Both alcohol and cigarettes very rarely appeared in the posts' visuals, in only less than $3 \%$ of posts. Of these, the celebrity was shown drinking alcohol and/or smoking cigarettes in two visuals, including Zayn Malik's Instagram photo in which he is seen with two friends holding a cigarette between his fingers. Nearly no visuals showcased the celebrity involved in a physical activity, and only slightly more than $5 \%$ did so, either explicitly or implicitly. Sex and sexual behaviors were nearly not at all a part of the visuals.

Table 5. Summary of Results RQ2b-Celebrities' Life-Style as Reflected in the Post ( $n, \%)$.

\begin{tabular}{|c|c|c|}
\hline The Celebrity & The Visual (pic/video) & The Celebrity in the Visual \\
\hline$N=1,075$ & $N=1,055$ & $N=786$ \\
\hline $\begin{array}{l}\text { Celebrity life-style: } \\
\begin{array}{l}\text { - } \\
\text { - } \quad \text { So signs }(998,92.84 \%) \\
\text { - } \quad \text { The most central topic of the post }(9, \\
\text { - } \quad \text { Undetermined }(5,0.47 \%) \\
\text { - } 1,5.86 \%) \\
\end{array}\end{array}$ & $\begin{array}{l}\text { Alcohol: } \\
\begin{array}{l}\text { - } \quad \text { Mentioned or depicted in post }(29 \text {, } \\
2.75 \%) \\
\text { - Not mentioned or depicted }(1,026 \text {, } \\
97.25 \%) \\
\text { Cigarettes: } \\
\text { - Mentioned or depicted in post (5, } \\
\text { 0.47\%) } \\
\text { Not mentioned or depicted (1050, } \\
99.53 \%)\end{array}\end{array}$ & 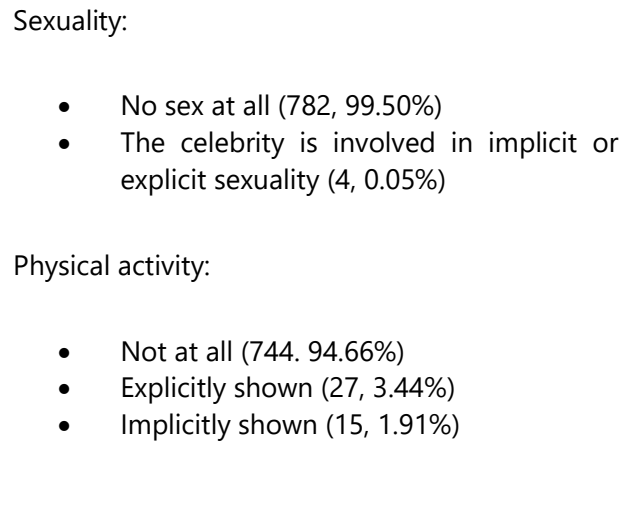 \\
\hline
\end{tabular}

The large majority of posts, nearly $93 \%$, did not reflect a celebrity life-style. A glimpse into such a life-style was offered through some signs in just above $5 \%$ of the posts and less than $1 \%$ specifically focused centrally on the celebrity's unique life-style. An example of a post reflecting a celebrity's lifestyle is Israeli actor Daniel Litman's Instagram post in which he is seen with his arms around two other celebrities whose names appear on the photo and the text: "You can see the joy in the eyes." The three clearly appear to be friendly with one another as they hang out together in an event.

\section{Discussion}

The study examined the SNS (Facebook and Instagram) presence of teen-preferred celebrities to characterize the breadth and depth of its content, messages, and self-disclosure, the extent to which it exhibits and promotes a celebrity lifestyle, and the physical representation of the celebrities in the posts within these SNSs. These issues are important because they are likely to appeal to young audiences who are preoccupied with the notion of fame and being associated with famous people at the same time as they are forming their personal identity (Mascheroni et al., 2015; Uhls \& Greenfield, 2012). Moreover, physical appearance, depth, and breadth of exposure are likely linked to parasocial relationships formed between young audience members and the celebrities (Duboff, 2016; Kurtin et al., 2018); these PSRs, in turn, likely relate to the quest for fame and other important attitudes among teens, such as narcissism and materialism. The study found that the celebrities' SNS presence is characterized by a strong focus on their professional lives (RQ1a) at the same time that it lacks depth in personal self-disclosure (RQ1b) and that their SNS self-constructed presence is rather nonprovocative in the values it promotes, in the lifestyle it exhibits (RQ2b), and in the celebrities' physical representation (RQ2a).

The strong emphasis on the celebrity's professional life is evident in that the most common topic addressed in posts is their job-related activity and achievements, followed by personal promotion. These topics were presented mostly in a serious tone, and only rarely did their presentation involve humor. Personal characteristics of the celebrities, as evident through their profile posts, were led by talent, friendliness, and professionalism. The posts' texts also mostly referred to the adoration of the celebrity or their talent. The visuals in the celebrities' posts also emphasized professionalism by mostly including backgrounds related to their profession, such as a studio or performance. They mostly showed the 
celebrities at least partially groomed and wearing casual and elegant clothing to create an overall attractive or very attractive appearance. What is missing from most posts is an extensive reference to their personal lives or lifestyle.

The focus on the celebrity's professional life is in line with the extended focus placed by media personae on publicizing the products of their professional activity. It is also consistent with the integrated marketing communication emphasis on establishing a clear brand image that is focused and coherent (Shimp, 2007). But the focus on the professional means that the celebrities leave out many topics from their SNS profiles. Especially surprising was the minimal mention in posts of social or political activism on the part of the celebrities. Only very rarely did these celebrities post about their involvement in mostly social causes. Perhaps the celebrities understand that their involvement in social activism does not necessarily lead to media coverage (Panis \& Van den Bulck, 2014), and is less likely to promote further public discussion outside of the SNS profile.

Another explanation for the strong focus on the celebrities' professional lives may be that the SNS personal profile enables the celebrity (and their social media management team) control over the image they choose to convey to the audience, especially in contrast to traditional and news media coverage which leaves the control in the hands of gatekeepers. Whereas traditional gatekeepers have increasingly been focusing on the personal and the negative of celebrity coverage (Marshall, 2010), celebrities use their personal profiles to communicate a more positive and controlled self-image (Marwick \& boyd, 2011a). This is also apparent in the physical self-selected visual representations of the celebrities in their posts which mostly focused on the upper portion of the body and the face and of the celebrity wearing casual clothing. As celebrity news media and the paparazzi prefer less aesthetic and more revealing photographs (McNamara, 2011), the celebrities themselves prefer to post visuals that are more polished, high quality, and professionally-crafted.

A third related explanation to the focus on the professional life of the celebrity is that in the SNSs, celebrities hope to address a wide audience. The heterogeneity of the audience and the need to maintain it, means that the celebrity needs to avoid offending members of the public and thus, best be non-provocative (for example, by leaving out any reference, mention, or depiction of more controversial behaviors such as those associated with cigarettes, alcohol, or sexuality) and avoid the potential danger of misunderstood humor or jokes. Most likely, the celebrities are also aware that within this audience, there is a large proportion of adolescents and thus, are even more careful to avoid provocations or offensive, age-inappropriate posts. In this context-collapse of back- and front-stage, celebrities need to make sure that no one becomes upset by their SNS dealing with a sensitive topic, as there may be real-world implications for their professional activity (Marwick \& boyd, 2011b; Todd, 2018; Wittkower, 2014). Likely, this is the reason that the most commonly addressed values in the celebrities' SNS posts were identified as liberalism, equality, and women empowerment, which may be less controversial contemporarily.

An alternative explanation to the findings regarding the lack of personal and provocative representation in celebrities' SNS profiles might be that these celebrities can sell information about their personal lives and events - sometimes for considerable amounts of money - to traditional media outlets (McNamara, 2011). There is no reason then, to expose personal events or post pictures from such events for free on the profile.

The findings reveal a paradoxical situation - on a platform on which almost everything is allowed and few restrictions exist outside of the hands of traditional gatekeepers, celebrities (and their social media management team) choose to present a very controlled and limited image of themselves in their personal profiles that is not provocative but also lacks depth and a personal feeling. It seems that celebrities are voluntarily enacting a strict self-regulation, carefully constructing and staging their image in these profiles (Marshall, 2010). Perhaps, similar to ordinary citizens, celebrities too fear privacy violations (Ampong et al., 2018), feasibly even more than others as they know the extent and cost of such violations.

From a parasocial relationship perspective, it is questionable if the celebrities' current pattern of representation in their SNS profiles is likely to promote such a relationship with audience members. In fact, the study's findings might help explain Bond's (2016) findings that Facebook and Instagram did little to contribute to PSRs with celebrities. Though SNSs likely promote brief parasocial interactions due to their breaking of the $4^{\text {th }}$ wall and the felt interactivity they enable between fans and celebrities, they should also, as Baruh and Cemalcılar (2018) emphasized, include personal selfdisclosure in order to establish long-standing PSRs. Such personal exposure was missing in the current sample. The lack of self-disclosure might harm PSR development as it may be associated with a lowered sense of authenticity. Many studies have equated authenticity with self-disclosure, which promotes a sense of intimate familiarity with and trust toward the celebrity. 
Perhaps, however, the definition of authenticity should be reconsidered or expanded, as suggested by Marwick and boyd (2011a). Beyond self-disclosure, a sense of authenticity might be associated with communicating messages that appear honest and complete, albeit not necessarily emotional, such as exposing the behind-the-scenes and backstage process of professional life, including productions, rehearsals, and experiences on stage and with co-workers. Likely, celebrities, like other young people, are concerned with exhibiting an authentic image of themselves (e.g., Thomas, 2014; Uski \& Lampinen, 2016). They may choose to do this by appearing candid, sincere, and realistic in their SNS representation of their professional lives (Cohen \& Tyler, 2016).

Though the celebrities whose SNS profiles were chosen for analysis in this study were selected based on teen preferences, it does not appear that their posts specifically target this young audience. Little specific reference to teen culture and interest was identified in this study (e.g., mentioning a teen-oriented television show or movie, promoting teen-targeted brands) and few explicit attempts to attract a teen audience were identified, such as communicating a sense of similarity to youth or extensive self-disclosure as is important for this audience. Rather, the celebrities, through their selfcensorship of their SNS profiles, seem to appeal to a broad audience, though one could argue that avoiding mentions of cigarettes, alcohol, and sexuality indicates that they are aware of their wide young following. Future research should examine what this general-audience appeal and focus on professionalism implicate for teens' fame-valuation as well as for their relationships with these celebrities. Perhaps celebrities' SNS presence as characterized in this study is associated less with PSRs but more with adoration, which is another form of tie audience members form with mediated personae (Cohen, 2001). Moreover, as the celebrities' personal profiles on SNSs are one form through which young audience members gain exposure to the celebrity, alongside traditional and news media and, especially paparazzi journalism and photographs, it would be interesting to examine how SNS following is related to PSRs and adoration relative to these other outlets.

\section{Limitations and Future Research Suggestions}

The current study provides a blueprint for future research into celebrity SNS communication in that it constructed a comprehensive codebook that considered the diverse and multiple components of SNS posts and their various subparts, including the visual element and the text. With that said, the sample of favorite celebrities for this study was determined based on public reports, lists, and publications of popular entertainment outlets claiming to represent the preferences of Israeli adolescents with regard to celebrities. An additional list could be constructed by asking adolescents directly for their preferred celebrities, in general, and those they choose to follow on SNSs, specifically.

Related to this, the current study only examined eight international celebrities. Future research can include more foreign celebrities and more cross-country comparisons of SNS posts and relationships with audiences. In addition, future analysis could take into consideration sub-groups within the greater definition of celebrities, such as celebrities who star or who have debuted in reality television shows and even those who have participated in reality shows in different stages of their "fame cycle" (Deller, 2016, p. 374). The audience might have different perceptions of celebrities based on their talent or background, including their willingness to take part in reality shows, and thus might treat such celebrities differently which might be associated with differences in how these celebrities "behave" online relative to other celebrities.

A third limitation is that any conclusions about the perceived authenticity of celebrity presence on SNSs and its influence on teens should be taken with caution as only a study directly asking adolescents for their beliefs and attitudes can provide such information. Future research should take into consideration adolescents' perspectives on celebrities' SNS posts in determining the codes in content analyses and should also examine the relationship between the celebrities' SNS presence and teen attitudes toward fame and being famous.

Fourth, the current study analyzed celebrity SNS presence at one point in time and on two social networks. Future research could extend this examination to additional SNSs that are central to celebrity online presence internationally (e.g., Twitter, YouTube) and also over time, to examine changes and developments in this realm. Differences between social networks should be taken into consideration as visual-based SNSs (e.g., Instagram) might provide different affordances than text-focuses SNSs (such as Twitter) and SNSs that allow lengthy posts (e.g., Facebook) might differ from those that restrict the parameters of posts (e.g., Twitter). Different SNSs might thus differ in the relationships whose development they encourage for the audience and in the extent to which the audience is an active participant in the maintenance of the famous persona (Kehrberg, 2015; Usher, 2015). Finally, it is important for future research to interview the celebrities themselves, along with their social media team, to understand their choices in posting on social networks 
from their perspective and ascertain the extent to which SNSs truly allow for control of information on the part of the celebrities.

\section{References}

Ampong, G. O. A., Mensah, A., Adu, A. S. Y., Addae, J. A., Omoregie, O. K., \& Ofori, K. S. (2018). Examining self-disclosure on social networking sites: A flow theory and privacy perspective. Behavioral Sciences, 8(6), Article 58. https://doi.org/10.3390/bs8060058

Aubrey, J. S., Behm-Morawitz, E., \& Kim, K. (2014). Understanding the effects of MTV's 16 and Pregnant on adolescent girls' beliefs, attitudes, and behavioral intentions toward teen pregnancy. Journal of Health Communication, 19(10), 1145-1160. https://doi.org/10.1080/10810730.2013.872721

Auter, P. J. (1992). Psychometric: TV that talks back: An experimental validation of a parasocial interaction scale. Journal of Broadcasting \& Electronic Media, 36(2), 173-181. https://doi.org/10.1080/08838159209364165

Baruh, L., \& Cemalcilar, Z. (2018). When more is more? The impact of breadth and depth of information disclosure on attributional confidence about and interpersonal attraction to a social network site profile owner. Cyberpsychology: Journal of Psychosocial Research on Cyberspace, 12(1), Article 1. https://doi.org/10.5817/CP2018-1-1

Behm-Morawitz, E., Aubrey, J. S., Pennell, H., \& Kim, K. B. (2019). Examining the effects of MTV's 16 and Pregnant on adolescent girls' sexual health: The implications of character affinity, pregnancy risk factors, and health literacy on message effectiveness. Health Communication, 34(2), 180-190. https://doi.org/10.1080/10410236.2017.1399506

Bond, B. J. (2016). Following your "friend": Social media and the strength of adolescents' parasocial relationships with media personae. Cyberpsychology, Behavior, and Social Networking, 19(11), 656-660.

http://doi.org/10.1089/cyber.2016.0355

boyd, d. (2007). Why youth [heart] social network sites: The role of networked publics in teenage social life. In D. Buckingham (Ed.), Youth, identity, and digital media (pp.119-142). MIT Press.

Chen, C.-P. (2016). Forming digital self and parasocial relationships on YouTube. Journal of Consumer Culture, 16(1), 232-254. https://doi.org/10.1177/1469540514521081

Chia, S. C., \& Poo, Y. L. (2009). Media, celebrities, and fans: An examination of adolescents' media usage and involvement with entertainment celebrities. Journalism \& Mass Communication Quarterly, 86(1), 23-44.

https://doi.org/10.1177/107769900908600103

Chung, S., \& Cho, H. (2017). Fostering parasocial relationships with celebrities on social media: Implications for celebrity endorsement. Psychology \& Marketing, 34(4), 481-495. https://doi.org/10.1002/mar.21001

Click, M. A., Lee, H., \& Holladay, H. W. (2013) Making monsters: Lady Gaga, fan identification, and social media. Popular Music and Society, 36(3), 360-379. https://doi.org/10.1080/03007766.2013.798546

Cohen, E. L., \& Tyler, W. J. (2016). Examining perceived distance and personal authenticity as mediators of the effects of ghost-tweeting on parasocial interaction. Cyberpsychology, Behavior, and Social Networking, 19(5), 342-346. https://doi.org/10.1089/cyber.2015.0657

Cohen, J. (2001). Defining identification: A theoretical look at the identification of audiences with media characters. Mass Communication and Society, 4(3), 245-264. https://doi.org/10.1207/S15327825MCS0403_01

Common Sense Media. (2015). The Common Sense census: Media use by tweens and teens.

https://www.commonsensemedia.org/sites/default/files/uploads/research/census_researchreport.pdf

Deller, R. A. (2016). Star image, celebrity reality television and the fame cycle, Celebrity Studies, 7(3), 373-389.

https://doi.org/10.1080/19392397.2015.1133313 
Dibble, J. L., Hartmann, T., \& Rosaen, S. F. (2016). Parasocial interaction and parasocial relationship: Conceptual clarification and a critical assessment of measures. Human Communication Research, 42(1), 21-44.

https://doi.org/10.1111/hcre.12063

Dror, Y., \& Gershon, S. (2012). Israelim ba-Idan ha-Digitali 2012 [Israelis in the Digital Age 2012. College of Management Academic Studies.

Duboff, J. (2016, October). Who's really pulling the strings (and pressing "send") on the social media accounts of the famous. Vanity Fair. https://www.vanityfair.com/style/2016/09/celebrity-social-media-accounts

Erikson, E. (1968). Identity: Youth and crisis. Norton.

Eyal, K., \& Dailey, R. M. (2012). Examining relational maintenance in parasocial relationships. Mass Communication and Society, 15(5), 758-781. https://doi.org/10.1080/15205436.2011.616276

Eyal, K., \& Finnerty, K. (2009). The portrayal of sexual intercourse on television: How, who, and with what consequence? Mass Communication and Society, 12(2), 143-169. https://doi.org/10.1080/15205430802136713

Eyal, K., Kunkel, D., Biely, E. N., \& Finnerty, K. L. (2007). Sexual socialization messages on television programs most popular among teens. Journal of Broadcasting \& Electronic Media, 51(2), 316-336.

https://doi.org/10.1080/08838150701304969

Fehr, B. (1996). Friendship processes. Sage.

Fu, X., Kou, Y., \& Yang, Y. (2015). Materialistic values among Chinese adolescents: Effects of parental rejection and selfesteem. Child \& Youth Care Forum, 44, 43-57. https://doi.org/10.1007/s10566-014-9269-7

Gabriel, S., Paravati, E., Green, M. C., \& Flomsbee, J. (2018). From apprentice to president: The role of parasocial connection in the election of Donald Trump. Social Psychological and Personality Science, 9(3), 299-307.

https://doi.org/10.1177/1948550617722835

Geurin-Eagleman, A. N., \& Burch, L. M. (2016). Communicating via photographs: A gendered analysis of Olympic athletes' visual self-presentation on Instagram. Sports Management Review, 19(2), 133-145.

https://doi.org/10.1016/j.smr.2015.03.002

Giles, D. C., \& Maltby, J. (2004). The role of media figures in adolescent development: Relations between autonomy, attachment, and interest in celebrities. Personality and Individual Differences, 36(4), 813-822.

https://doi.org/10.1016/S0191-8869(03)00154-5

Gleason, T. R., Theran, S. A., \& Newberg, E. M. (2017). Parasocial interactions and relationships in early adolescence. Frontiers in Psychology, 8, Article 255. https://doi.org/10.3389/fpsyg.2017.00255

Gorin, V., \& Dubied, A. (2011). Desirable people: Identifying social values through celebrity news. Media, Culture, \& Society, 33(4), 599-618. https://doi.org/10.1177/0163443711398695

Greenwood, D. N. (2013). Fame, Facebook, and Twitter: How attitudes about fame predict frequency and nature of social media use. Psychology of Popular Media Culture, 2(4), 222-236. https://doi.org/10.1037/ppm0000013

Greenwood, D., McCutcheon, L. E., Collisson, B., \& Wong, M. (2018). What's fame got to do with it? Clarifying links among celebrity attitudes, fame appeal, and narcissistic subtypes. Personality and Individual Differences, 131, 238-243. https://doi.org/10.1016/j.paid.2018.04.032

Holmes, S. (2005). 'Off-guard, unkempt, unready'? Deconstructing contemporary celebrity in heat magazine. Continuum: Journal of Media \& Cultural Studies, 19(1), 21-38. https://doi.org/10.1080/1030431052000336270 
Horton, D., \& Wohl, R. R. (1956). Mass communication and para-social interaction: Observations on intimacy at a distance. Psychiatry: Interpersonal and Biological Processes, 19(3), 215-229.

https://doi.org/10.1080/00332747.1956.11023049

Hull, K., \& Lewis, N. P. (2014). Why Twitter displaces broadcast sports media: A model. International Journal of Sport Communication, 7(1), 16-33. https://doi.org/10.1123/IJSC.2013-0093

Israel National Council for the Child. (2017). Ha-Shnaton Ha-Statisti "Yeladim be-Israel 2017" Leket Netunim [The annual statistics: Children in Israel 2017. A collection of data]. https://www.children.org.il/wpcontent/uploads/2018/08/pdf_merged.pdf

Jayson, S. (2013, April 18). Survey: Young people who use social media seek fame. USA Today. https://www.usatoday.com/story/news/nation/2013/04/18/social-media-tweens-fame/2091199/

Jiménez, Á. V., \& Mesoudi, A. (2019). Prestige-biased social learning: Current evidence and outstanding questions. Palgrave Communications, 5, Article 20. https://doi.org/10.1057/s41599-019-0228-7

Kehrberg, A. K. (2015). 'I love you, please notice me': The hierarchical rhetoric of Twitter fandom. Celebrity Studies, 6(1), 85-99. https://doi.org/10.1080/19392397.2015.995472

Kim, J., \& Song, H. (2016). Celebrity's self-disclosure on Twitter and parasocial relationships: A mediating role of social presence. Computers in Human Behavior, 62, 570-577. https://doi.org/10.1016/j.chb.2016.03.083

Kowalczyk, C. M., \& Pounders, K. R. (2016). Transforming celebrities through social media: The role of authenticity and emotional attachment. Journal of Product \& Brand Management, 25(4), 345-356. https://doi.org/10.1108/JPBM-092015-0969

Kurtin, K. S., O'Brien, N., Roy, D., \& Dam, L. (2018). The development of parasocial relationships on YouTube. Journal of Social Media in Society, 7(1), 233-252. https://thejsms.org/index.php/TSMRI/article/view/304/160

Labrecque, L. I. (2014). Fostering consumer-brand relationships in social media environments: The role of parasocial interaction. Journal of Interactive Marketing, 28(2), 134-148. https://doi.org/10.1016/j.intmar.2013.12.003

Ledbetter, A. M., \& Redd, S. M. (2016). Celebrity credibility on social media: A conditional process analysis of online self-disclosure attitude as a moderator of posting frequency and parasocial interaction. Western Journal of Communication, 80(5), 601-618. https://doi.org/10.1080/10570314.2016.1187286

Lewallen, J., Miller, B., \& Behm-Morawitz, E. (2016). Lifestyles of the rich and famous: Celebrity media diet and the cultivation of emerging adults' materialism. Mass Communication and Society, 19(3), 253-274.

https://doi.org/10.1080/15205436.2015.1096945

Lunardo, R., Gergaud, O., \& Livat, F. (2015). Celebrities as human brands: An investigation of the effects of personality and time on celebrities' appeal. Journal of Marketing Management, 37(5-6), 685-712.

https://doi.org/10.1080/0267257X.2015.1008548

Madden, M., Lenhart, A., Cortesi, S., Gasser, U., Duggan, M., Smith, A., \& Beaton, M. (2013, May 21). Teens, social media, and privacy. Pew Research Center: Internet \& Technology. https://www.pewresearch.org/internet/2013/05/21/teenssocial-media-and-privacy/

Maltby, J., Houran, J., \& McCutcheon, L. (2003). A clinical interpretation of attitudes and behaviors associated with celebrity worship. The Journal of Nervous and Mental Disease, 191(1), 25-29. https://doi.org/10.1097/00005053200301000-00005

Marshall, P. D. (2010). The promotion and presentation of the self: Celebrity as marker of presentational media. Celebrity Studies, 1(1), 35-48. https://doi.org/10.1080/19392390903519057 
Marshall, P. D. (2014). Celebrity and power: Fame in contemporary culture (2nd. ed.). University of Minnesota Press.

Marwick, A., \& boyd, d. (2011a). To see and be seen: Celebrity practice on Twitter. Convergence: The International Journal of Research into New Media Technologies, 17(2), 139-158. https://doi.org/10.1177/1354856510394539

Marwick, A. E., \& boyd, d. (2011b). I tweet honestly, I tweet passionately: Twitter users, context collapse, and the imagined audience. New Media \& Society, 13(1), 114-133. https://doi.org/10.1177/1461444810365313

Mascheroni, G., Vincent, J., \& Jimenez, E. (2015). "Girls are addicted to likes so they post semi-naked selfies": Peer mediation, normativity and the construction of identity online. Cyberpsychology: Journal of Psychosocial Research on Cyberspace, 9(1), Article 5. https://doi.org/10.5817/CP2015-1-5

McNamara, K. (2011). The paparazzi industry and new media: The evolving production and consumption of celebrity news and gossip websites. International Journal of Cultural Studies, 14(5), 515-530.

https://doi.org/10.1177/1367877910394567

Moraes, M., Gountas, J., Gountas, S., \& Sharma, P. (2019). Celebrity influences on consumer decision making: New insights and research directions. Journal of Marketing Management, 35(13-14), 1159-1192.

https://doi.org/10.1080/0267257X.2019.1632373

Mortensen, M., \& Jerslev, A. (2014). Taking the extra out of the extraordinary: Paparazzi photography as an online celebrity news genre. International Journal of Cultural Studies, 17(6), 619-636.

https://doi.org/10.1177/1367877913503425

Moyer-Gusé, E. (2008). Toward a theory of entertainment persuasion: Explaining the persuasive effects of entertainment-education messages. Communication Theory, 18(3), 407-425. https://doi.org/10.1111/j.14682885.2008.00328.x

Panis, K., \& Van den Bulck, H. (2014). In the footsteps of Bob and Angelina: Celebrities' diverse societal engagement and its ability to attract media coverage. Communications, 39(1), 23-42. https://doi.org/10.1515/commun-2014-0003

Phua, J., Jin, S. V., \& Kim, J. J. (2017). Gratifications of using Facebook, Twitter, Instagram, or Snapchat to follow brands: The moderating effect of social comparison, trust, tie strength, and network homophily on brand identification, brand engagement, brand commitment, and membership intention. Telematics \& Informatics, 34(1), 412-424.

https://doi.org/10.1016/j.tele.2016.06.004

Potter, W. J., \& Levine-Donnerstein, D. (1999). Rethinking validity and reliability in content analysis. Journal of Applied Communication Research, 27(3), 258-284. https://doi.org/10.1080/00909889909365539

Rubin, R. B., \& McHugh, M. P. (1987). Development of parasocial interaction relationships. Journal of Broadcasting \& Electronic Media, 31(3), 279-292. https://doi.org/10.1080/08838158709386664

Rui, R. J., \& Stefanone, M. A. (2016). The desire for fame: An extension of uses and gratifications theory. Communication Studies, 67(4), 399-418. https://doi.org/10.1080/10510974.2016.1156006

Saleem, S., Larimo, J. A., Ummik, K., \& Kuusik, A. (2015). Cultural and paradoxical values in advertising in Eastern Europe: Evidence from Estonia. Baltic Journal of Management, 10(3), 313-330. https://doi.org/10.1108/BJM-11-20140202

Shimp, T. A. (2007). Integrated marketing communications in advertising and promotion (7th ed.). Thomson Higher Education.

Siibak, A. (2009). Constructing the self through the photo selection - Visual impression management on social networking websites. Cyberpsychology: Journal of Psychosocial Research on Cyberspace, 3(1), Article 1.

https://cyberpsychology.eu/article/view/4218/3260 
Smith, K. C., Twum, D., \& Gielen, A. C. (2009). Media coverage of celebrity DUls: Teachable moments or problematic social modeling? Alcohol and Alcoholism, 44(3), 256-260. https://doi.org/10.1093/alcalc/agp006

Soukup, C. (2006) Hitching a ride on a star: Celebrity, fandom, and identification on the World Wide Web. Southern Communication Journal, 71(4), 319-337. https://doi.org/10.1080/10417940601000410

Spies Shapiro, L. A., \& Margolin, G. (2014). Growing up wired: Social networking sites and adolescent psychosocial development. Clinical Child and Family Psychology Review, 17(1), 1-18. https://doi.org/10.1007/s10567-013-0135-1

Stever, G. S., \& Lawson, K. (2013). Twitter as a way for celebrities to communicate with fans: Implications for the study of parasocial interaction. North American Journal of Psychology, 15(2), 339-354.

Te'eni-Harari, T., \& Eyal, K. (2015). Liking them thin: Adolescents' favorite television characters and body image. Journal of Health Communication, 20(5), 607-615. https://doi.org/10.1080/10810730.2015.1012241

Thomas, S. (2014). Celebrity in the 'Twitterverse': History, authenticity and the multiplicity of stardom Situating the 'newness' of Twitter. Celebrity Studies, 5(3), 242-255. https://doi.org/10.1080/19392397.2013.845962

Tian, Q., \& Hoffner, C. A. (2010). Parasocial interaction with liked, neutral, and disliked characters on a popular television series. Mass Communication and Society, 13(3), 250-269. https://doi.org/10.1080/15205430903296051

Todd, L. (2018, May 30). Eight times celebrities messed up on social media. BBC News.

https://www.bbc.com/news/entertainment-arts-44302767

Tsay-Vogel, M., \& Schwartz, M. L. (2014). Theorizing parasocial interactions based on authenticity: The development of a media figure classification scheme. Psychology of Popular Media Culture, 3(2), 66-78.

https://doi.org/10.1037/a0034615

Tukachinsky, R., Inaba, H., Kraus, K., Schubert, D., \& Williams, M. (2019). Sex, likes and Instagram: Celebrity selfpresentation on Instagram images. In C. M. Madere (Ed.), How celebrity lives affect our own: Understanding the impact on Americans' public and private lives (pp. 165-179). Rowman \& Littlefield.

Tzavela, E. C., \& Mavromati, F. M. (2013). Online social networking in adolescence: Associations with development, well-being and internet addictive behaviors. International Journal of Child and Adolescent Health, 6(4), 411-420.

Uhls, Y. T., \& Greenfield, P. M. (2011). The rise of fame: An historical content analysis. Cyberpsychology: Journal of Psychosocial Research on Cyberspace, 5(1), Article 1. https://cyberpsychology.eu/article/view/4243/3289

Uhls, Y. T., \& Greenfield, P. M. (2012). The value of fame: Preadolescent perceptions of popular media and their relationship to future aspirations. Developmental Psychology, 48(2), 315-326. https://doi.org/10.1037/a0026369

Uhls, Y. T., Zgourou, E., \& Greenfield, P. M. (2014). 21st century media, fame, and other future aspirations: A national survey of 9-15 year olds. Cyberpsychology: Journal of Psychosocial Research on Cyberspace, 8(4), Article 5. https://doi.org/10.5817/CP2014-4-5

Usher, B. (2015). Twitter and the celebrity interview. Celebrity Studies, 6(3), 306-321. https://doi.org/10.1080/19392397.2015.1062641

Uski, S., \& Lampinen, A. (2016). Social norms and self-presentation on social network sites: Profile work in action. New Media \& Society, 18(3), 447-464. https://doi.org/10.1177/1461444814543164

Van den Bulck, H., Paulussen, S., \& Bels, A. (2017). Celebrity news as hybrid journalism: An assessment of celebrity coverage in Flemish newspapers and magazines. Journalism, 18(1), 44-63. https://doi.org/10.1177/1464884916657523

Wiederhold, B. K. (2012). As parents invade Facebook, teens tweet more. Cyberpsychology, Behavior, and Social Networking, 15(8), 385-385. http://doi.org/10.1089/cyber.2012.1554 
Wittkower, D. E. (2014). Facebook and dramauthentic identity: A post-Goffmanian model of identity performance on SNS. First Monday, 19(4). https://doi.org/10.5210/fm.v19i4.4858

\title{
Correspondence to:
}

Keren Eyal

Sammy Ofer School of Communications

Interdisciplinary Center (IDC) Herzliya

8 University St.

4610101 Herzliya

Israel

Email: keyal(at)idc.ac.il

Editorial record: First submission received on March 24, 2019. Revisions received on September 26, 2019, October 2, 2019, January 27, 2020 and February 25, 2020. Accepted for publication on March 2, 2020.

Editor in charge: Lenka Dedkova

\begin{abstract}
About Authors
Keren Eyal, Ph.D., is a Senior Lecturer in the Sammy Ofer School of Communication at the Interdisciplinary Center (IDC) Herzliya. Her primary research interests include media content and effects, with a developmental focus and an emphasis on social and cognitive process involved in media exposure.
\end{abstract}

Tali Te'eni-Harari, Ph.D., is the head of the MBA program at the School of Business Administration in the Peres Academic Center. Her primary research interests include advertising information processing among young people and its effects on young people.

Keshet Katz, M.Sc., is a researcher at StoreNext Research and Strategy in Israel. Her research interests include social media effects, marketing research, and consumer behavior. 